\title{
Toward equal participation: An auto-ethnography of facilitating consultations in the refugee sector
}

Sue Elliott

Sue Elliott is a lecturer at Unitec Institute of Technology where she is a Curriculum Leader for the Bachelor of Social Practice.

\section{Abstract}

This article uses an auto-ethnographic approach to exploring how one positions oneself as a facilitator in a layered and power-laden context in the refugee sector in New Zealand to ensure just and collaborative negotiations. It reflects on my facilitation practice based during a series of annual consultations between UNHCR, NGOs and refugee community representatives over a period of five years. The article begins by providing a brief overview of the New Zealand refugee system. This is followed by a review of relevant literature on the role of the facilitator and the role of facilitation within community development, an acknowledged field of social work. Reflections on facilitation practice within an ethnically diverse situation makes up the bulk of the article, which is written from the perspective of a Pakeha woman who has worked in the refugee sector for nearly 35 years, most recently in community development and capacity building of refugee-based organisations.

This paper adopts a relatively descriptive style to a personal reflection on facilitating large consultations in the refugee sector in New Zealand. For ease of reading, the term refugee is used throughout, although the consultations focus on both refugee and asylum issues. As presented here, my reflexive analysis is interwoven with research and literature on facilitation and reflects who I am and what I value, in a myriad of tacit and overt ways. It focuses on the facilitation process and the role of the facilitator rather than on the outcomes of the consultations. I have deliberately focused on my own story as I consider this is the story I can ethically tell.

\section{Background}

Nearly 34 million people around the world live in the limbo-land of exile as refugees (UNHCR, 2012). The term refugee is used loosely in public discourse, but the 1951 United Nations Convention relating to the Status of Refugees (and the 1967 Protocol), which are central to the international refugee regime, defines a refugee as someone who:

...owing to well-founded fear of being persecuted for reasons of race, religion, nationality, membership of a particular social group or political opinion, is outside the country of his nationality and is unable or, owing to such fear, is unwilling to avail himself of the protection of that country (UNHCR). 
The Convention also established the United Nations High Commission for Refugees (UNHCR) which is... 'mandated to lead and coordinate international action to protect refugees and resolve refugee problems worldwide' (The Office of the United Nations High Commissioner for Refugees, 2012a). UNHCR's work focuses on three areas: legal protection, resettlement and public information. The UNHCR Regional Office, based in Canberra, covers Australia, New Zealand, Papua New Guinea and the South Pacific.

Most refugees come to New Zealand via the government Refugee Quota Programme which resettles 750 refugees a year. Each year, New Zealand also processes applications for refugee status from approximately 300 asylum seekers in search of international protection from persecution. A further group from refugee-like situations join family members in New Zealand through various other immigration policies, particularly the Refugee Family Support Category (Searle, Prouse, L'Ami, Gray, \& Gruner, 2012).

New Zealand is now a very multi-ethnic country, building on a strong bicultural foundation based on the Treaty of Waitangi which promised equal rights and privileges for the indigenous Māori population and subsequent settlers. Ethnic diversity has increased over the past 20 years due to changes in immigration policy. Approximately 50,000 refugees have resettled in New Zealand since the end of World War Two (Ministry of Health, 2012). Data from the 2013 Census shows that 'there are more ethnicities in New Zealand than there are countries in the world' (Statistics New Zealand, 2013) and people from a refugee background contribute greatly to the country's ethnic diversity. Nearly $70 \%$ of refugees who come to New Zealand live in Auckland (Searle et al., 2012), where one in five residents were born overseas. Given this diversity, facilitating groups which contain participants from a wide range of cultures is now the norm in New Zealand.

Over the last 25 years, refugees in New Zealand have moved past being passive recipients of welfare assistance and services and being spoken for by others to having a strong voice themselves. For example, the National Refugee Network (NRN), composed of representatives from the regional refugee leaders, provides a collective voice for refugees at a national level. The NRN is based on the basic principle of: 'Nothing about us should be without us: People from refugee-backgrounds should be involved in all stages of policy or service delivery development' (Refugee Sector Strategic Alliance, 2013). This has resulted in increased refugee participation in the formation of the policies and services that impact upon their communities, a sense of increased empowerment and improved responsiveness of services provided to people from a refugee background (Gruner \& Searle, 2011).

\section{Community development and facilitation}

Most publications about facilitation provide a brief definition of facilitation. As a working definition in this article, I am drawn to Bens' (2012 p. 8) definition as, 'One who contributes the structure and process to interactions so that groups are able to function effectively... A helper and enabler whose goal is to support others as they pursue their objectives'.

This definition clearly sets out the role of a facilitator. A number of writers stress the need for neutrality or objectivity (often used interchangeably) and freedom from conflicts of interest as core values (Strachan, 2007) in facilitation. Sometimes a distinction is made 
regarding content neutrality versus process neutrality. I believe that we cannot act neutrally to ensure that notions of social justice, or participation, are enacted. Ensuring social justice and participation requires conscious effort and is an integral part of facilitation.

A number of other key values are seen as necessary to underpin ethical facilitation. For Strachan (2007) good facilitation practice is underlined by the values of 'integrity, authenticity and mutual respect'. Rees (2005) also stresses the need to be authentic and centred while holding onto one's values, even in stressful facilitation situations. Hogan (2007) stresses participation, equity, empowerment, having a voice and the right to speak out; yet the refugee experience often denies these tenets.

The choice of whether or not to use an internal or external facilitator parallels insider / outsider debates. Ideas of insider or outsider stem from Merton's (1972) seminal work which, put simply, stated that to be an insider 'you have to be one in order to understand one.' Hellawell (2006) comments that Merton believes insiders are those who a priori possess knowledge of a community and its members, but nuanced relationships can evade outsiders, who no matter their knowledge or skill are excluded as a matter of principle. However, Hellawell (2006) believes that 'ideally the researcher should be both inside and outside the perceptions of the 'researched.' Taking this position leads us to the notion that insiders or outsiders are on a continuum, rather than being discrete points. Similarly there are advantages and disadvantages in employing both internal and external facilitators (Hogan, 2002, p.54).

Participation is fundamental to community development (Hogan, 2007 ) and therefore facilitation skills are essential for community development workers. Ife (2013) includes the roles of mediation, negotiation, support, consensus building, group facilitation and personal communication as those most essential for community development workers. In my work as a facilitator all of these skills are relevant.

In a group setting the facilitator plays the roles of partner, planner, enabler, motivator, taskmaster and guide (Wilkinson, 2012). The facilitator therefore needs to have a sound understanding of a range of methods and approaches to ensure participation. However good facilitators also need to be able to analyse the immediate context in which they work (including participants' values) and simultaneously be able to draw on a range of past experiences (Strachan, 2007). Alongside being conscious of the role of the facilitator, and the methodologies used, the facilitator needs to decide how a given meeting will be structured. Being clear of your role and position as a facilitator and the complex layers of the task, are central to ensuring to consultations or meetings are successful.

The rest of this paper reflects on my facilitation of the annual UNHCR consultations over a period of six years.

\section{Method}

The idea for this article emerged after a conversation with the UNHCR Representative about possible reasons why the consultation discussions under consideration had deepened over the years, resulting in more useful and effective meetings. After the conversation I wanted to understand more about the part my own role as the facilitator played in this change. 
A facilitator needs to maintain the stance of a participant observer (Strachan, 2007), staying attuned to the dynamics in the room whilst remaining true to the contract with the group and the client (in this case, UNHCR). Reflection is essential in order to be effective and facilitators therefore need continuously to examine their own practice. Consequently, the underpinning approach taken in this article is critical, reflexive, auto-ethnographic practice informed by critical race theory and intercultural communication principles.

Auto-ethnography is a useful methodology for researchers and practitioners in multicultural settings such as these consultations and can lead to greater understanding for the researcher of their own practice (Chang, 2008 p. 51). Auto-ethnography can also assist in examining the assumptions that are usually overlooked but influence our actions in life and work (Muncey, 2010, p,xi). Furthermore, reflexivity researchers consciously reveal their beliefs and values when selecting their research methodologies and writing about their research (Hellawell, 2006) .

Further, I believe there is a role for facilitators working in the refugee sector to provide leadership to overcome social injustices such as those that have impacted the lives of refugees. Yet most literature on facilitation relegates ethnic diversity to only a few paragraphs under the heading of 'dealing with cultural differences'. There are of course exceptions to this practice (see for example Hogan, 2007). Consideration of these two factors further motivated me to explore my own practice.

Alongside consideration of my role as facilitator, I am also mindful of the ethics of refugee research which demand the, 'intersecting issues of power and consent, confidentiality and trust, ... as well as the broader cross-cutting issues of gender, culture, human rights and social justice' (Pittaway, Bartolomei, \& Hugman, 2010). Many of these cross-cutting issues emerge in the consultations and how I address them as a facilitator are discussed below. A further reason for focusing on facilitation rather than the content of the issues arising during discussions stems from the consultation ground rules which are based on Chatham House Rules (which aim at encouraging openness and the sharing of information by allowing participants 'to use the information they receive but neither the identity nor affiliation of the speaker(s), nor that of any other participant may be revealed') (Chatham House, 2014). Furthermore I have an ethical concern for relationships as I will live within the community discussed long after any research is published (Ellis, Adams, \& Bochner, 2011).

Having worked in a range of capacities in the refugee sector for many years (as a teacher, facilitator, researcher, consultant, volunteer, ally, friend and lecturer on refugee issues both in New Zealand and internationally) I know many of the meeting participants. Several also know my partner is an African from a refugee background. Living in this partnership involves many conversations about the nature of refugeehood, and requires intercultural communication and negotiation on a daily basis and therefore heightens my awareness of the sorts of issues that emerge in the consultations. Some African participants know me well and claim me as a sister-in-law on occasions. This claim also means they will, and have, assisted me in difficult and tense situations in the consultations, but they also hold an expectation that I will support the positions or arguments they put forward during the meeting. Sometimes I decide to ask them to set this pseudo-familial relationship aside in order for me to wear a 'facilitator's' hat, with all the complexity that entails. I reveal this snippet of personal information as an illustration of how an auto-ethnographic approach involves 
self-exposure, cultural analysis and interpretation (Chang, 2008, p. 51). We cannot separate who we are from what we do (Muncey, 2010). My personal and professional background inevitably informs my understanding and positioning in relation to my role as a facilitator and as a researcher in this small study.

Data for this study have been drawn from personal reflections, observations and notes jotted during the consultations, final meeting reports and participant evaluations.

\section{The meetings}

Since 2007 UNHCR has hosted an annual consultation between refugee representatives and Non-Governmental Organisations (NGOs) working in the refugee sector in New Zealand. UNHCR's aim in holding the consultations in question is to: identify and discuss key issues for people from a refugee background and refugee-assisting NGOs; gauge NGO/refugee community views on ways of strengthening liaison and dialogue with UNHCR in order to analyse trends and issues to assist to develop priorities; and develop work plans and cooperation with others in the following year. I have facilitated all but one of these meetings.

Whilst not expounding on the issues that arise during the meeting, Table one provides a summary of the scope and complexity of the perennial issues that arise and need to be discussed meaningfully in the space of one day.

Table one. Issues discussed during consultations.

UNHCR Mandate

Legal protection

Resettlement

Public information/ advocacy

\section{Issues arising}

Refugeehood in an international context

The NZ Immigration Act

Customs / Border control

Immigration profiling

Composition of the annual Refugee Quota

Increasing voice and leadership of people from a refugee background

The national refugee resettlement strategy

The struggle to match available resources to needs

Barriers to employment

Negative images of refugees in the media

Measures to increase the awareness of the positive contributions people from refugee backgrounds make to New Zealand society

Participation in the meeting is by a letter of invitation from UNHCR. Attendance at the consultations has increased from 18 in 2007 to 65 in 2014. About half the participants come from a refugee background (from Afghanistan, Myanmar, Burundi, Ethiopia, Nepal, Eritrea, Somalia, D. R. Congo, Kurdistan and South Sudan), reflecting a number of languages and cultures within each national border. The other half are from refugee-assisting NGOs, and there are some former refugees employed in refugee-assisting NGOs who therefore hold dual identities in the meeting. More men than women represent refugee communities with the opposite being true for NGO representation. The first consultation was held in an NGO 
training room. The following year it moved to a local-government community venue and for the past five years it has been held at a hotel conference centre.

\section{Reflections}

One of the early decisions UNHCR needs to make in regards to the consultations is whether or not to use an internal or an external facilitator. The consultations are complex and reasonably large-scale, the topics of the consultation can be contentious, and there is a chance that a facilitator from UNHCR would not appear sufficiently neutral. Increasingly, policy makers have realised that complex problems require collaborative solutions as traditional problem-solving methods have failed to deliver (Twyford, Waters, Hardy, \& Dengate, 2012). Considering all of these factors led UNHCR to decide upon employing an external facilitator for the consultations. However, I believe the role of facilitator can slide along the insider / outsider or internal/external continuum. In many ways I am an insider-outsider because of my experience and personal situation. I am not an employee of any of the groups attending, but have worked for many organisations present (including UNHCR) on a voluntary and/ or consultancy basis. My knowledge of the concepts (which some external facilitators would find difficult) and of the issues, history, position, and politics of the people and groups involved, increases the ease of discussions and therefore the communication between groups.

The communication process is influenced by a number of factors outside of the actual consultation discussions. The choice of a hotel conference venue helps confer status and convey the seriousness of the meeting. Attending to the various dietary requirements of such a diverse group and making sure that there is a private prayer space, ensures participants feel welcome and normalises diversity. The invitation is to participate in discussions, not just attend (Neal \& Neal, 2011, p. 42).

Being authentic in the setting means that in the preparation process I need to be able to envisage myself in the room where the meeting will occur. In order to do this requires a visit to the venue ahead of the consultation. Sometimes this is a cursory visit to remind myself of the space; at other times I am able to spend some time in the space visualising the layout, where the flipchart stand will be placed, where the UNHCR staff will be seated etc. The room set up may look seamless and inconsequential to participants, yet I know considerable energy has gone into the arrangements.

After UNHCR sends out the invitations to attend I follow up by contacting key representatives from the refugee community organisations to ensure the intention of the meeting is clear and appropriate background to any issue on the agenda is provided (as suggested by Landale \& Douglas, 2008, p. 29). This contact assists in further establishing rapport with key participants and ensuring that refugee voices and issues are heard.

Knowing the context and the issues also aids the design and meeting process. The parameters guiding the discussions, how the agenda will be achieved, the methods used, and who will speak (and in which order) need to be clear (Bens, 2012, p. 21) to assist in overcoming any intercultural misunderstandings.

Attention to how the meeting is started and concluded also influences the success of the consultations. Ensuring a direct relationship between UNHCR and the participants means 
a backseat role for the facilitator at times. The meeting is opened by the UNHCR Regional Representative, reflecting the status invested in his position. Other sessions are led by relevant staff members from UNHCR. However, the role of beginning the meeting process falls on me as the facilitator and I am aware that participants form an opinion of me in my role very quickly in a meeting (Hogan, 2002, p. 72).

In order to quickly build rapport with the group I have a tendency to joke, hoping to break the ice (Bens, 2012) and put people at ease. Laughter can counterbalance the darkness of some of the issues discussed (Lefeuvre, 2003), and can reduce stress, diffuse tension, build a group feeling and flatten power hierarchies (Plester, 2009). However, in intercultural settings it can be hard to get right, and 'may well be anglocentric' (Rogerson-Revell, 2007). So despite 30 years' experience in intercultural settings, the struggle to get away from my own cultural constructs surfaces, but thankfully the participants' reactions show that my jokes are usually at an appropriate pitch, and help put people at ease.

Consciously focusing on fundamental facilitation principles (as put forward by Hogan, 2007 ) is intrinsic to the meetings' success. In designing and conducting the consultation, the facilitator needs to focus on a process that pulls together a culturally diverse group, which can result in a richness of ideas thereby revealing the often silenced voices of people who have lived through a refugee experience and hold many insights that 'experts' can miss. Refugee issues are so complex and multifaceted they require the wisdom, insights and contributions from many people in order to develop a resettlement system in which people can rebuild meaningful lives.

A detailed facilitation plan to guide the meeting process is developed alongside the agenda. As the nature of discussions has deepened and become more nuanced over the years, I have used different facilitation methods. Choosing the methodology and how to guide the process is a live issue requiring a flexible approach. The meetings cannot be formulaic, nor can the facilitator ever expect they will be straightforward. There's no downtime for the facilitator; morning and afternoon tea are spent checking the consultation is on track and lunchtime usually means synthesising the morning's work, in clear language, to feed into afternoon sessions.

One of the most important things I have learned about facilitation is the need and art of being constantly present and focused on what is happening at a number of different levels, 'even if the group is not aware of this' (Rees, 2005, p. 363). There are no fixed rules in facilitation (Hogan, 2002, p. 52), so even with careful planning, decisions about where to go with discussions need to be made on one's feet, all the while retaining the relationships of trust amongst the facilitator, refugee community members, NGO representatives and UNHCR. Over the years, people in the refugee sector have gotten to know each other well. These relationships are crucial to ensuring communication misunderstandings, as well as overt and covert perceptions of the issues and their influences on communication are understood (Rowe \& Paterson, 2010) and surfaced. Good communication is essential in order to build trust and respect. It is important that the facilitator makes it clear that everyone's ideas are important and will receive consideration. Teasing out all the layers of relationships and the dynamics of inter-cultural communication is beyond the scope of this commentary; but the relationships are multifaceted and when combined with the seriousness of the content discussed, the complexity of the meetings is evident. 
The participants from refugee communities are not a homogenous group in terms of power and influence, nor is it safe to generalise about or stereotype how a specific ethnic group will behave. A number of dynamics can influence the process and some patterns can be identified. Some participants have been resident in New Zealand for only a few years, while others have been citizens for nearly 20 years. Gender divisions often impact on power dynamics, and the ways in which women and men behave in meetings varies between cultures (Hogan, 2007), class and whether refugees come from a rural or urban area. Different age groups from the same culture can also see things very differently. Cultural precepts can mean that older men speak before younger men and men before women; ensuring all voices are heard therefore requires a range of methods, questioning techniques, small and larger group discussions, all carefully chosen to assist mitigating power differences, if only temporarily (Rees, 2005, p. 363). With only one day allocated for a given meeting, the agenda is tight. Some participants come from cultures where long discussions, reiteration and overstating a point or an issue are the norm. Some wish to confront authority, while others shy away from conflict or putting forward opinions when people of status are present. Again being constantly present, being able to fall back on a broad repertoire of facilitation methods and knowing participants well enough so they will accept interventions to guide a debate yet surface deep-felt opinions all assist me to keep the process on track.

The way power works in the wider group also impacts on the communication and meeting process and needs the constant attention of the facilitator. The most marginalised participants receive priority speaking rights as their voices are least often heard. At times ensuring quieter voices are heard is hard work and the facilitator's authority is needed to ensure these voices count. At other times power needs to be handed over to the group to make decisions. The style of facilitation used depends on the context and the issues. It is important to keep a constant focus on when to move between styles to ensure participants are not frustrated or feel the meeting has lost course (Landale \& Douglas, 2008, p. 89). Most facilitators have a stock of techniques they use to ensure the momentum of a meeting is maintained. Not all methods rely on spoken or written language as using these methods alone can disadvantage some. Ranking and rating techniques can work well in multicultural groups to ensure everyone's opinion is considered. At least one of these facilitation methods is included during these meetings, especially when issues need to be prioritised.

Despite my striving to choose methods that encourage people to participate, some attendees come to the meeting for several years until their confidence and knowledge of New Zealand norms and mores grows enough for them to venture an opinion. This situation highlights the need for facilitators to provide safe spaces for people to trial a variety of forms of dialogue (Hogan, 2007) and methods to encourage interaction so that their voices can be rightly heard.

The UNHCR consultations are held in English which is the second (or third or fourth) language of many participants. Instructions need to be given and points summarised clearly, but without dumbing down the content and therefore patronising participants. In this context the language background of participants requires complete attention and presence in all debates and processes; not only for the facilitator, but for all participants as they need to concentrate to understand the diversity of ideas, meanings and arguments (Hogan, 2002, p. 68) as conveyed in a range of accents and styles. 
Understandably, passions can run high about certain issues or in relationships between groups. Yet, accepting that there are many ways of viewing the world is central to cultural competence (Phillips, 2009) which is demanded of all attending, but particularly of me as facilitator. Being aware of these dynamics, containing and (hopefully) resolving them requires alertness, and the active support of the wider group which can only be achieved through trust and open dialogue.

Despite not being formally part of the structure of any organisation taking part in the consultation, my expertise means participants have a level of expectation that I will contribute to the debates, so it is difficult to stay out of the content of the discussions at times. Yet, maintaining a facilitative role and guiding the process is vital to the flow of dialogue between the parties. In balancing this tension, it is crucial that the power invested in the facilitator's role is used appropriately to assist the consultation to meet its aims and to enhance the empowerment of those attending; especially those from a refugee background as their voices are often silenced in public debate.

As attendees have come to value the meetings more, and UNHCR's invitation and intentions have become clear and authenticated (Neal \& Neal, 2011, p. 41), the number of participants has increased markedly over the years, as noted above. Over time participants have come to perceive the event as a genuine consultation. For me it would be unprofessional to agree to facilitate the consultations if they were anything less than genuine, and such a decision would have ramifications in both my personal and professional life.

Communication during the meeting occurs as a dialogue across and between the many cultures in the room. UNHCR provides updates and an explanation of international situations, processes, procedures and norms which helps inform and increase knowledge. They also keep participant expectations realistic by reminding them of the limits of their mandate. UNHCR's clarity is another crucial element of intercultural communication. Communicating information clearly and being open about UNHCR's work helps build trust and cooperation.

UNHCR staff actively listen to the ideas and opinions put forward so that they can be incorporated in planning; but they also make it clear that they retain decision making over their own processes. UNHCR's insistence on Chatham House Rules provides for greater openness on all sides and increases the level of trust and depth of the exchanges. This openness is in contrast to situations where official agencies make their decisions before a consultation process, turning meetings such as these into frustrating window dressing exercises and undermining trust (Hogan, 2002, p.38). UNHCR clearly shows openness to 'hearing, valuing and using the ideas of those less powerful than themselves' (Hogan, 2007, p. 98) and that they are genuine in sponsoring the consultation (Twyford et al., 2012) through the stated objectives of the meeting and through their conduct during the process. Unless UNHCR staff behaviour demonstrates that they trust the consultation process (Twyford et al., 2012), the meetings will be unsuccessful. Similarly, they have to trust me as a facilitator in order for the meetings to be useful.

During the meeting it is important that all participant contributions are respectfully acknowledged, and then paraphrased to clarify the key points, which are then written on a flip chart; using these two forms of acknowledgement increases understanding among 
the diverse grouping present. Acknowledging participant contributions is essential; as it is disempowering when facilitators and agencies appear to be consulting but selectively fail to record ideas (Hogan, 2002, p. 39), thereby skewing the process. The main points raised and any agreements reached are summarised and circulated to all participants by UNHCR after the meeting as another way of valuing the diverse opinions presented.

At the end of the meeting, before the more formal closing, I summarise the main points that emerged during the day as a way of reinforcing consensus in terms of underlying goals and agreed actions (Ife, 2013). The summary overtly signals that the end point of the meeting has arrived as a result of everyone's opinions having been fairly aired (Twyford et al., 2012).

Written evaluation forms are usually circulated and collected towards the end of the meeting. Evaluations of the consultation are increasingly positive, and the feedback they provide is used in planning the meeting the following year. Participants' comments noting the meetings' success factors include respect, dignity and the benefits of hearing multiple voices to assist improving the lives of people who are resilient, despite enduring persecution and displacement.

But the meeting's closing remarks come from the UNHCR Representative; after all it's their meeting.

\section{Conclusion}

Despite the complexity of facilitating in such an intercultural milieu where different cultures, identities, manifestations of power, languages and issues are contenting with one another the meetings have become a valued event in the annual calendar of refugee community leaders and NGOs. However, it is easy to assume that facilitators in any consultation or community development setting just stand at the front of the room and record discussions on a flipchart. Yet reflection on the process from the point of view of the facilitator and how participant contributions to debates intertwine with complex layers in relation to ethnicity and gender in a diverse cultural setting, highlights the multifaceted nature of the facilitation process. It is essential that people from a refugee background are included and genuinely heard in consultations about refugee policy developments as they are the ones who are most affected by decision makers. To ensure that the participation of people from a refugee background is meaningful and on an equal footing with that of others, requires genuine intent on behalf of consultation holders. The facilitator needs to pay attention to careful preparation, choice of methodology and an appropriate venue selection. The onus is on the facilitator to reflect deeply on their own practice to ensure they set up the meeting appropriately, are confident and understand the complexity of the issues being debated, are respectful of the contributions of all participants, are skilled in a range of methods and are constantly mindful that the heart of their role is to guide the process in order to make difficult discussions as easy as possible.

\section{References}

Bens, I. (2012). Facilitating with ease!: Core skills for facilitators, team leaders and members, managers, consultants, and trainers. San Francisco: Jossey-Bass Business \& Management Series.

Chang, H. (2008). Autoethnography as method. Walnut Creek, California: Left Coast Press. 
Chatham House. (2014). Chatham House Rules. Retrieved from http:/ / www.chathamhouse.org/about-us/chathamhouserule.

Ellis, C., Adams, T., \& Bochner, A. (2011). Autoethnography: An overview. Forum Qualitative Social Research, 12(1). Retrieved from http: / / www.qualitative-research.net/index.php/fqs/article/view/1589/3095.

Gruner, A., \& Searle, W. (2011). New Zealand's refugee sector: Perspectives and developments, 1987-2010. Wellington, New Zealand: Department of Labour. New Zealand Government.

Hellawell, D. (2006). Inside-out: Analysis of the insider-outsider concept as a heuristic device to develop reflexivity in students doing qualitative research. Teaching in Higher Education, 11(4), 483-494.

Hogan, C. (2002). Understanding facilitation: Theory and principle. London: Kogan Page.

Hogan, C. (2007). Facilitating multicultural groups: A practical guide. London: Kogan Page.

Ife, J. (2013). Community development in an uncertain world: Vision, analysis and practice. Cambridge: Cambridge University Press.

Landale, A., \& Douglas, M. (2008). The fast facilitator. Amherst: HRD Press.

Lefeuvre, P. (2003). Working among the misery of refugees and asylum seekers. Pulse, 2 June 2003.

Merton, R. (1972). Insiders and outsiders: A chapter in the sociology of knowledge. American Journal of Sociology, 78(1).

Ministry of Health. (2012). Refugee health care: A handbook for professionals. Wellington, NZ: Author. Retrieved from http: / / www.health.govt.nz / system / files / documents / publications / refugee-health-care-a-handbook-forhealth-professionalsv2.pdf.

Muncey, T. (2010). Creating autoethographies. London: SAGE.

Neal, C., \& Neal, P. (2011). The art of convening: Authentic engagement in meetings, gatherings and consultations. San Francisco: Berrett-Koehler Publishers.

Phillips, A. (2009). Intercultural knowledge and skills in social service work with refugees. Journal of Ethnographic $\mathcal{E}$ Qualitative Research, 3(3), 185-195.

Pittaway, E., Bartolomei, L., \& Hugman, R. (2010). 'Stop stealing our stories': The ethics of research with vulnerable groups. Journal of Human Rights Practice, 2(2), 229-251.

Plester, B. (2009). Healthy humour: Using humour to cope at work. Kotuitui: New Zealand Journal of Social Sciences Online, 4(1), 89-102.

Rees, F. (2005). The facilitator excellence handbook. New York: Pfeiffer.

Refugee Sector Strategic Alliance. (2013). Code of ethics. NZ.

Rogerson-Revell, P. (2007). Humour in business: A double-edged sword. A study of humour and style shifting in intercultural business meetings. Journal of Pragmatics, 39(1).

Rowe, J., \& Paterson, J. (2010). Culturally competent communication with refugees. Home Health Care Management Practice, 22(5), 334-338.

Searle, W., Prouse, E., L'Ami, E., Gray, A., \& Gruner, A. (2012). New land, new life: Long-term settlement of refugees in New Zealand. Main Report: Labour and Immigration Research Centre, Labour Group, Ministry of Business, Innovation and Employment.

Statistics New Zealand. (2013). New Zealand has more ethnicities than the world has countries. Retrieved from http: / / www.stats.govt.nz / Census / 2013-census / data-tables / totals-by-topic-mr1.aspx.

Strachan, D. (2007). Making questions work: A guide to how and what to ask for facilitators, consultants. San Francisco: Jossey Bass.

The Office of the United Nations High Commissioner for Refugees. (2012a). The state of the world's refugees: In Search of Solidarity. A synthesis. J. Kumin (Ed.). Retrieved from http:/ / www.unhcr.org/4fc5ceca9.html.

The Office of the United Nations High Commissioner for Refugees. (2012b). The state of the world's refugees: In search of solidarity. A synthesis. UNHCR.

Twyford, V., Waters, S., Hardy, M., \& Dengate, J. (2012). The power of Co: A smart leader's guide to collaborative governance. Twyfords.

UNHCR. (1951). The 1951 Refugee Convention. Retrieved from http: / www.unhcr.org/pages/49da0e466.html.

Wilkinson, M. (2012). The secrets of facilitation: The SMART guide to getting results with groups. San Francisco: Jossey Bass. 